\title{
How Does Silicon Mediate Plant Water Uptake and Loss Under Water Deficiency?
}

\author{
Daoqian Chen ${ }^{1,2}$, Shiwen Wang ${ }^{1,3 *}$, Lina Yin ${ }^{1,3}$ and Xiping Deng ${ }^{1,3}$ \\ 'State Key Laboratory of Soil Erosion and Dryland Farming on the Loess Plateau, Institute of Soil and Water Conservation, \\ Northwest A\&F University, Yangling, China, ${ }^{2}$ College of Crop Science, Fujian Agriculture and Forestry University, Fuzhou, \\ China, ${ }^{3}$ Institute of Soil and Water Conservation, Chinese Academy of Sciences and Ministry of Water Resources, Yangling, \\ China
}

\section{OPEN ACCESS}

Edited by:

Erik T. Nilsen,

Virginia Tech, United States

Reviewed by:

Steven Jansen,

University of Ulm, Germany

Walter Chitarra,

Consiglio per la Ricerca in Agricoltura e l'Analisi dell'Economia Agraria

(CREA), Italy

Dimitrios Savvas,

Agricultural University of Athens,

Greece

${ }^{*}$ Correspondence:

Shiwen Wang

shiwenwang@nwsuaf.edu.cn

Specialty section:

This article was submitted to

Plant Abiotic Stress,

a section of the journal

Frontiers in Plant Science

Received: 13 December 2017

Accepted: 19 February 2018

Published: 05 March 2018

Citation:

Chen D, Wang S, Yin L and Deng X (2018) How Does Silicon Mediate Plant Water Uptake and Loss Under Water Deficiency?

Front. Plant Sci. 9:281. doi: 10.3389/fpls.2018.00281
In plants, water deficiency can result from a deficit of water from the soil, an obstacle to the uptake of water or the excess water loss; in these cases, the similar consequence is the limitation of plant growth and crop yield. Silicon (Si) has been widely reported to alleviate the plant water status and water balance under variant stress conditions in both monocot and dicot plants, especially under drought and salt stresses. However, the underlying mechanism is unclear. In addition to the regulation of leaf transpiration, recently, Si application was found to be involved in the adjustment of root hydraulic conductance by up-regulating aquaporin gene expression and concentrating $\mathrm{K}$ in the xylem sap. Therefore, this review discusses the potential effects of Si on both leaf transpiration and root water absorption, especially focusing on how Si modulates the root hydraulic conductance. A growing number of studies support the conclusion that Si application improves plant water status by increasing root water uptake, rather than by decreasing their water loss under conditions of water deficiency. The enhancement of plant water uptake by $\mathrm{Si}$ is achievable through the activation of osmotic adjustment, improving aquaporin activity and increasing the root/shoot ratio. The underlying mechanisms of the Si on improving plant water uptake under water deficiency conditions are discussed.

\section{Keywords: silicon, water status, water balance, drought, salt stress, transpiration, water uptake}

\section{INTRODUCTION}

Silicon $(\mathrm{Si})$ is the second most abundant element in soil. Plants generally take up $\mathrm{Si}$ in the form of soluble monosilicic acid $\mathrm{H}_{4} \mathrm{SiO}_{4}$, which normally ranges from 0.1 to $0.6 \mathrm{mM}$ in the soil solution (Ma and Yamaji, 2006). All terrestrial plants contain Si in their tissues although the contents of Si varies considerably among species, ranging from 0.1 to $10 \% \mathrm{Si}$ on a dry weight basis ( $\mathrm{Ma}$ and Yamaji, 2006; Cornelis et al., 2010; Sahebi et al., 2015). Si has not been recognized as an essential element for plant growth, it does exert beneficial effects for many plant species, including both monocots and dicots (Ma and Yamaji, 2015). Indeed, Si seems to alleviate the detrimental effects of various stresses, including drought, salinity, heat, cold, metal toxicity, nutrient imbalance, plant pathogens, and insect pests (Liang et al., 2007; Guntzer et al., 2012; Hernandez-Apaolaza, 2014; Zhang et al., 2014; Meharg and Meharg, 2015; Vivancos et al., 2015; Guo et al., 2016; Reynolds et al., 2016).

Water deficiency is one of the major environmental constraints of plant growth and crop productivity (Chaves and Oliveira, 2004; Verslues et al., 2006). Plant water deficiency may result from a shortage of water in soil (drought) or from an obstacle to water uptake (physiological 
drought). Plant water deficiency can also be caused by the excessive high vapor pressure deficit in the atmosphere, which results in higher rates of water loss via transpiration than the rates of water transport to the leaves (Mahajan and Tuteja, 2005). In these cases, plant water status is disturbed, resulting in disruption of important metabolic processes and reduction in growth rates (Verslues et al., 2006). Hence, investigating mechanisms of plants' ability to tolerate water stress may lead to an understanding of how to increase water stress resistance. Recently, improvement of plant resistance to drought, osmotic, and salt stresses have been widely observed after the addition of Si to the growth medium (Zhu and Gong, 2014; Rizwan et al., 2015; Coskun et al., 2016; Helaly et al., 2017).

Several different aspects are involved in Si-improved plants' resistance to drought or salt stress, including maintenance of nutrient balance, promotion of photosynthetic rate, increasing antioxidant capacity, and sequestration of toxic ions (Ma, 2004; Liang et al., 2007; Sacała, 2009; Zhu and Gong, 2014; Rizwan et al., 2015). Moreover, various compounds of Si, including 1-2 mM $\mathrm{Na}_{2} \mathrm{SiO}_{3}, \mathrm{~K}_{2} \mathrm{SiO}_{3}$ or $\mathrm{H}_{2} \mathrm{SiO}_{3}$, either applied in the soil or the nutrient solution, are showed to improve the water status of plants experiencing drought or salt stress (Romero-Aranda et al., 2006; Sacała, 2009; Liu et al., 2014, 2015). In addition, it has been reported that supplement with $1 \mathrm{mM} \mathrm{H}_{2} \mathrm{SiO}_{3}$ in the nutrient solution can alleviate $\mathrm{K}$ deficiency, which also causes tissue dehydration (Chen et al., 2016). A variety of beneficial effects of Si application could be ascribed to the alleviation of problematic water status in those studies by decreasing the transpiration rate, increasing the osmotic adjustment capacity, or increasing water uptake (Liang et al., 2007; Sacała, 2009; Zhu and Gong, 2014; Rizwan et al., 2015). In this review, we address recent results that are relevant to the Si effect, and assess what they mean for the interpretation of how Si improves plant water status and enables the maintenance of plant water balance under water deficiency condition.

\section{SILICON CONTRIBUTES TO ALLEVIATION OF PLANT WATER STATUS UNDER STRESS CONDITIONS}

A common consequence of several abiotic stresses is the disturbance of plant water status. Abiotic stresses, such as drought, salinity, and freezing have a common impact on plant cells in decreasing the availability of water (Mahajan and Tuteja, 2005; Verslues et al., 2006), quantified as a decrease in plant water potential and relative water content. Conversely, maintenance of higher relative water contents indicates a better water status (Verslues et al., 2006).

Under drought stress, the beneficial effect of Si on plant water status has been extensively examined in various plant species, including sorghum (Hattori et al., 2007; Yin et al., 2013; Ahmed et al., 2014), wheat (Gong and Chen, 2012), maize (Amin et al., 2014), rice (Ming et al., 2012), cucumber (Ma et al., 2004), Kentucky Bluegrass (Saud et al., 2014), canola (Habibi, 2014), sunflower (Gunes et al., 2008), chickpea (Gunes et al., 2007), soybean (Shen et al., 2010), alfalfa (Liu and Guo, 2013), and tomato (Shi et al., 2016). The improvements of relative water content and/or water potential by Si application occurred under both polyethylene glycol-induced osmotic stress (Hattori et al., 2007; Ming et al., 2012) and potted soil drought conditions (Gong et al., 2003; Amin et al., 2014). In addition, it has been showed that in the leaves of Si-treated wheat, both relative water contents and the water potential were maintained to a greater extent compared to that without Si-treatment, suggesting that Si could also be used to improve the water status of wheat under field drought conditions (Gong and Chen, 2012).

Under salt stress condition, the beneficial role of $\mathrm{Si}$ in mitigating the adverse effects of salinity by preventing root $\mathrm{Na}^{+}$ uptake and/or its transport from roots to shoots has been widely reported (Liang et al., 2007; Savvas et al., 2007, 2009; Zhu and Gong, 2014; Savvas and Ntatsi, 2015). In addition to ion toxicity, high concentrations of salts in solution also cause osmotic stress in plants, because they limit the availability of water, affecting water status and leaf growth (Munns and Tester, 2008). Chen et al. (2014) reported that Si could alleviate the salt stress in both two phases of growth inhibition, with the alleviative effects being more pronounced in the osmotic stress phase than ion toxicity phase. Moreover, Si application is widely reported to improve the leaf relative water contents and/or leaf water potential under salt stress in wheat (Tuna et al., 2008), rice (Yeo et al., 1999), sorghum (Liu et al., 2015), maize (Parveen and Ashraf, 2010), tomato (Li et al., 2015), Phaseolus vulgaris (Zuccarini, 2008), sunflower (Ashraf et al., 2015), and cucumber (Wang et al., 2015). The only exception to these findings was the observation that Si decreased tomato leaf water potential under salt stress (Romero-Aranda et al., 2006). However, in this study, plant water content in salinized plants supplied with Si was $40 \%$ higher than in salinized plants without $\mathrm{Si}$, and leaf turgor potential and net photosynthetic rates were much higher in salinized plants with $\mathrm{Si}$. Therefore, in spite of the leaf water potential, it can be concluded that $\mathrm{Si}$ improves the water status of tomato under salt stress.

A recent study in sorghum showed that $\mathrm{Si}$ could alleviate potassium (K) deficiency by improving plant water status (Chen et al., 2016). $\mathrm{K}$ is the most abundant cation in plants and plays a key role in osmotic processes that contribute to cellular turgor, photosynthesis, and transpiration (Wang and Wu, 2013). $\mathrm{K}$ is involved in regulating the plant water status, and severe $\mathrm{K}$ deficiency causes tissue dehydration (Kanai et al., 2011). Moreover, it has also been reported that $\mathrm{Si}$ could enhance freezing stress resistance in freezing-susceptible wheat cultivar by alleviating water-deficit stress that caused by freezing-induced cellular dehydration (Liang et al., 2008).

\section{SILICON CONTRIBUTES TO MAINTAINING HIGHER TRANSPIRATION UNDER STRESS CONDITIONS}

Under normal growth conditions, water is absorbed by the roots and lost from the leaves, and plants keep a proper water balance by continuously adjusting these two processes (Maurel and Chrispeels, 2001). Under water deficient conditions, the plant's first response is to avoid low water potential by adjust 
their water balance between root water uptake and leaf water loss (Luu and Maurel, 2005; Verslues et al., 2006). Plants can reduce leaf water loss by controlling the transpiration rate and also by decreasing their leaf area. Under normal growth conditions, only a few reports have shown that $\mathrm{Si}$ affects the transpiration rate. The pioneering researchers in this field reported that $\mathrm{Si}$ application can reduce the excessive leaf transpiration in rice and sugarcane under normal growth conditions; they postulated that this effect could be due to the reduction in transpiration rate through cuticular layers thickened by silica deposits (Yoshida, 1965; Savant et al., 1996). However, other researchers reported that rather than due to the thickness of cuticular layers, the reduced transpiration levels of Si-fed maize and rice were primarily due to the lower transpiration through stomatal pores (Agarie et al., 1998; Gao et al., 2004, 2006), which mainly ascribed to the turgor loss of guard cells originating from Si deposition and changing of the physical and mechanical properties of their cell walls (Ueno and Agarie, 2005; Savvas and Ntatsi, 2015). The reduced transpiration rates caused by $\mathrm{Si}$ were also reported in upland rice and cucumber in the absence of stress (Ma et al., 2004; Ming et al., 2012). Despite these reports, Si application has been found to have no effect on transpiration rates under normal growth conditions in the vast majority of studies (Hattori et al., 2005, 2009; Chen et al., 2011; Gong and Chen, 2012). We suspect that the conflicting results are due to species and genotypic variations since we have noticed that the effects of $\mathrm{Si}$ on reducing the transpiration rate under normal growth conditions tend to appear in the species and genotypes with high Si accumulation and high contribution of cuticular transpiration to total transpiration.

When plants first begin to experience drought stress, they decrease the leaf water loss mainly by decreasing the leaf transpiration rate through stomatal closure. Conflicting reports exist in the literature regarding the impact of $\mathrm{Si}$ on leaf transpiration rate. Maize leaf transpiration is reported to be decreased by Si in the studies of Gao et al. $(2004,2006)$ and Amin et al. (2014). Liu and Guo (2013) reported that Si application reduced both the transpiration rate and stomatal conductance but had no effect on photosynthetic rate in alfalfa under drought stress. Although, it has been reported that Si reduced the excessive leaf transpiration in rice under normal growth conditions (Savant et al., 1996; Agarie et al., 1998; Ming et al., 2012), the results of Chen et al. (2011) and Ming et al. (2012) showed that rice leaf transpiration was enhanced by $\mathrm{Si}$ when the plants were experiencing drought. Many other results on drought stressed plants have been shown to be consistent with enhanced leaf transpiration by Si application (Hattori et al., 2005; Sonobe et al., 2009; Chen et al., 2011; Gong and Chen, 2012; Pereira et al., 2013; Zhang et al., 2013; Liu et al., 2014; Saud et al., 2014; Kang et al., 2016). Under salt stress, the leaf transpiration rate has also been widely reported to be enhanced by Si (Yeo et al., 1999; Parveen and Ashraf, 2010; Liu et al., 2015; Wang et al., 2015; Mahmood et al., 2016; Qin et al., 2016). Also relevant are the findings of Chen et al. (2016), who reported that Si application enhances the transpiration of sorghum experiencing K-deficiency. Therefore, we conclude that Si application generally enhances transpiration of plants under various conditions of water stress.

\section{SILICON ENHANCES ROOT WATER UPTAKE UNDER STRESS CONDITIONS}

During water deficiency, the regulation of root water uptake, in some cases, may be more crucial to overcome stress injury than the regulation of leaf water loss (Aroca et al., 2012). Compared with the effect of Si on the leaf transpiration, fewer studies have focused on the impact of Si on root water uptake. Root water uptake capacity is represented by root hydraulic conductance (Steudle, 2000). Recently, improving root hydraulic conductance by $\mathrm{Si}$ application has been directly demonstrated in sorghum (Hattori et al., 2007; Sonobe et al., 2009, 2010; Liu et al., 2014), rye (Hattori et al., 2009), tomato (Shi et al., 2016), and cucumber (Wang et al., 2015; Zhu et al., 2015) under drought stress, salt stress and $\mathrm{K}$ deficiency conditions.

The extent of root hydraulic conductance depends on the driving force, root surface area, root anatomy, and root's permeability to water (Steudle, 2000; Vandeleur et al., 2009; Sutka et al., 2011). A promotion of osmotic driving force by $\mathrm{Si}$ application has been observed in various studies.

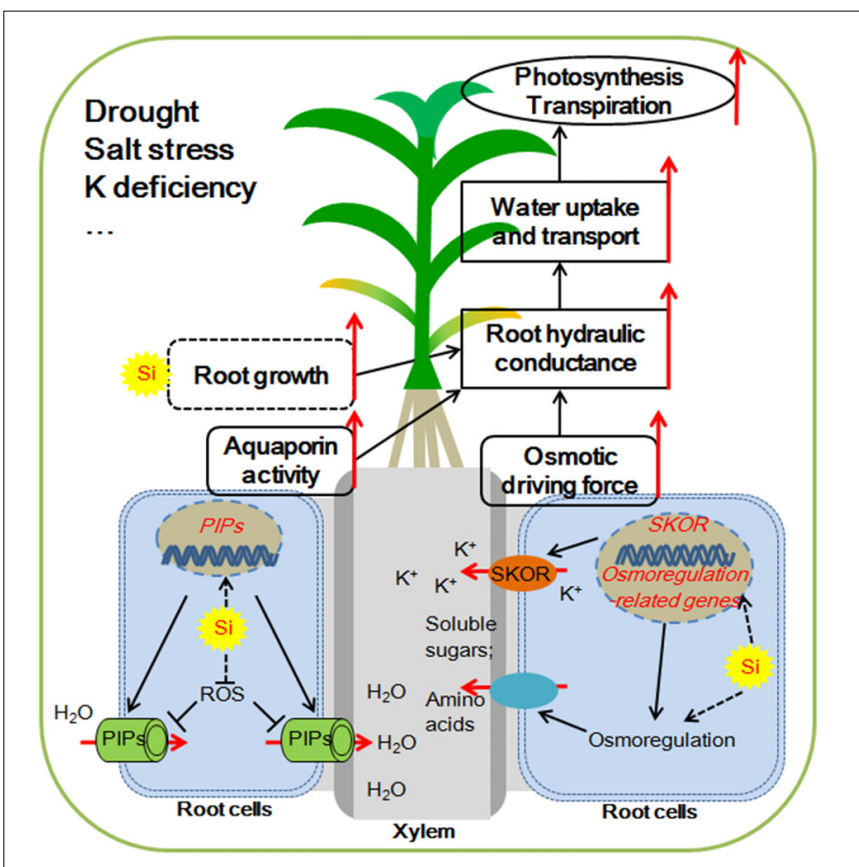

FIGURE 1 | Possible mechanisms for silicon (Si) mediated water balance of plants experiencing water deficiency. (1) Si enhances the aquaporin activity by up-regulating the expression of Plasma membrane Intrinsic Protein (PIP) aquaporin genes and alleviating the ROS (reactive oxygen species)-induced aquaporin activity inhibition. (2) Si enhances the accumulation of soluble sugars and/or amino acids in the xylem sap by osmorugulation; Si activates the $\mathrm{K}^{+}$translocation to xylem sap by the activation the expression of $S K O R$ (Stelar $K^{+}$Outward Rectifer) gene. The osmolyte accumulations in the xylem sap increase the osmotic driving force. (3) Si might adjust the root growth and increase root/shoot ratio, which together with enhancement of aquaporin activity and osmotic driving force contribute to the improvement of root hydraulic conductance. The higher root hydraulic conductance results in increased uptake and transport of water, which helps to maintain a higher photosynthetic rate and improve plant resistance to water deficiency. 
Sonobe et al. (2010) suggested that Si application leads to a strong water potential gradient through accumulation of soluble sugars and amino acids in the plant. A similar consequence of Si application was observed in rice (Ming et al., 2012) and canola (Habibi, 2014) under drought stress. Liu et al. (2015) reported that Si had no effect on osmotic potential of root xylem sap under osmotic stress although it increased root hydraulic conductance in sorghum (Liu et al., 2015). In the study of tomato under osmotic stress, water stress also did not cause the change in root osmotic potential in Si-treated plants (Shi et al., 2016). Under salt stress, Zhu et al. (2015) found that Si decreased root xylem osmotic potential via accumulation of soluble sugars in cucumber. Under $\mathrm{K}$ deficiency condition, Si was also seen to decrease the root xylem osmotic potential through accumulation of $\mathrm{K}$ in sorghum (Chen et al., 2016). Therefore, under those conditions, regulation of the osmotic driving force could play a central role in Si-mediated enhancement of water uptake.

In addition to driving force, aquaporins were reported to play a central role in regulating root water permeability in response to short term water stress (Maurel et al., 2008). Liu et al. (2014) firstly reported that Si-pretreatment significantly increased the expression of aquaporin genes, which in turn increased the root water uptake in sorghum under drought stress. Recently, Liu et al. (2015) and Zhu et al. (2015) also observed that $\mathrm{Si}$ application increased aquaporin expression in sorghum and cucumber under salt stress. In addition, Si can also increase aquaporin expression in sorghum under $\mathrm{K}$ deficiency (Chen et al., 2016). However, the expression of aquaporin genes was not significantly regulated (less than twofold) by $\mathrm{Si}$ application in tomato under water stress (Shi et al., 2016). It is worth noting here that only three aquaporin genes (SIPIP1; 3, SlPIP1; 5, and SIPIP2; 6) were studied in this tomato study. Furthermore, modulation of aquaporin transport activity can also occur at post-transcriptional level. It is speculated that increased root hydraulic conductance by $\mathrm{Si}$ under stress conditions may be partly ascribed to $\mathrm{Si}$-induced reductions in oxidative stress and membrane damage (Li et al., 2015; Shi et al., 2016). Similarly, Liu et al. (2015) suggested that Si could enhance aquaporin activity by reducing $\mathrm{H}_{2} \mathrm{O}_{2}$ accumulation. Certainly, it can be concluded that regulation of aquaporin transport activity is involved in Si-induced enhancement of root hydraulic conductance under stress conditions. But whether it is a general mechanism for the enhancement of root hydraulic conductance under stress conditions requires further study.

When long-term water stress occurred, changes in root surface and anatomy may also be important for enhancing plant water uptake (Javot and Maurel, 2002). Under drought stress, Sipretreatment has been reported to increase the root/shoot ratio, contributing to a higher ability of water uptake in sorghum (Hattori et al., 2005, 2009). The increased root/shoot ratio was also observed in other studies of sorghum (Ahmed et al., 2011a,b) and rice (Ming et al., 2012) under drought stress as well as cucumber under salt stress (Wang et al., 2015). These results suggest that Si-mediated modifications of root growth may also account for the increase in the water uptake ability in Si-treated plants. However, Liu et al. (2014) did not observe any $\mathrm{Si}$-mediated changes in vessel diameter or vessel number of sorghum root under drought stress. And several researchers observed no effect of $\mathrm{Si}$ on the root/shoot ratio in other plant species under stress conditions (Gong et al., 2003; Gao et al., 2004; Sonobe et al., 2009; Chen et al., 2011; Shi et al., 2016). In summary, Si-mediated modification of root growth may enhance root water uptake under stress conditions, but this adjustment is not a common phenomenon to all plants and it remains unclear whether $\mathrm{Si}$ is directly involved in the modification of root growth or not. Further studies are needed to clarify how Si regulates root development under water deficient condition.

\section{CONCLUSION AND PERSPECTIVES}

Water deficiency is one of the major environmental factors limiting the growth of plants and the production of crops. The investigations described here showed that Si application moderates the plant hydraulic properties by increasing the root water uptake, but not by decreasing their water loss under water deficient condition. As illustrated in Figure 1, the potential key mechanisms involved in Si-mediated enhancement of plant root water uptake under water deficiency include: (1) enhancement of the osmotic driving force via active osmotic adjustment; (2) improvement of aquaporin transport activity at both transcriptional and post-transcriptional levels; (3) modification of root growth and increasing root/shoot ratio (Figure 1).

Predictions of future global environmental changes point to an increase in both the severity and frequency of water stress in the near future. Therefore, genetic and biochemical manipulation of crops to increase their capacities of Si absorption, translocation and distribution from applied Si fertilizer should be considered as a preferable choice to improve crop production under water deficient condition. However, the mechanisms behind the beneficial effects of $\mathrm{Si}$ are still largely unknown. Hence, the mechanisms by which Si moderates the plant water status still need further investigation, especially regarding the molecular and biochemical basis by which Si regulates plant water uptake. In addition, the application of $\mathrm{Si}$ and its performance under field conditions still needs extensive investigation.

\section{AUTHOR CONTRIBUTIONS}

SW and DC wrote the manuscript. LY and XD helped in drafting the manuscript.

\section{FUNDING}

This study was supported by the National Natural Science Foundation of China (Grant No. 31101597), National Key Technology Support Program of China (Grant No. 2015BAD22B01), and 111 Project of Chinese Education Ministry (Grant No. B12007). 


\section{REFERENCES}

Agarie, S., Uchida, H., Agata, W., Kubota, F., and Kaufman, P. B. (1998). Effects of silicon on transpiration and leaf conductance in rice plants (Oryza sativa L.). Plant Prod. Sci. 1, 89-95. doi: 10.1626/pps.1.89

Ahmed, M., Asif, M., and Hassan, F. (2014). Augmenting drought tolerance in sorghum by silicon nutrition. Acta Physiol. Plant. 36, 473-483. doi: 10.1007/ s11738-013-1427-2

Ahmed, M., Fayyaz-Ul-Hassen, and Khurshid, Y. (2011a). Does silicon and irrigation have impact on drought tolerance mechanism of sorghum? Agric. Water Manag. 98, 1808-1812. doi: 10.1016/j.agwat.2011.07.003

Ahmed, M., Fayyaz-Ul-Hassen, Qadeer, U., and Aslam, M. A. (2011b). Silicon application and drought tolerance mechanism of sorghum. Afr. J. Agric. Res. 6, 594-607. doi: 10.5897/AJAR10.626

Amin, M., Ahmad, R., Basra, S. M. A., and Murtaza, G. (2014). Silicon induced improvement in morpho-physiological traits of maize (Zea Mays L.) under water deficit. Pak. J. Agric. Sci. 51, 187-196.

Aroca, R., Porcel, R., and Manuel Ruiz-Lozano, J. (2012). Regulation of root water uptake under abiotic stress conditions. J. Exp. Bot. 63, 43-57. doi: 10.1093/jxb/ err266

Ashraf, M., Abid, M., Da Silva, J. A. T., Shahzad, S. M., Hussain, A., and Imtiaz, M. (2015). Silicon and potassium nutrition enhances salt adaptation capability of sunflower by improving plant water status and membrane stability. Commun. Soil Sci. Plant Anal. 46, 991-1005. doi: 10.1080/00103624.2015. 1018527

Chaves, M. M., and Oliveira, M. M. (2004). Mechanisms underlying plant resilience to water deficits: prospects for water-saving agriculture. J. Exp. Bot. 55, 2365-2384. doi: 10.1093/jxb/erh269

Chen, D., Cao, B., Wang, S., Liu, P., Dneg, X., Yin, L., et al. (2016). Silicon moderated the $\mathrm{K}$ deficiency by improving the plant-water status in sorghum. Sci. Rep. 6:22882. doi: 10.1038/srep22882

Chen, D. Q., Yin, L. N., Deng, X. P., and Wang, S. W. (2014). Silicon increases salt tolerance by influencing the two-phase growth response to salinity in wheat (Triticum aestivum L.). Acta Physiol. Plant. 36, 2531-2535. doi: 10.1007/s11738014-1575-z

Chen, W., Yao, X. Q., Cai, K. Z., and Chen, J. N. (2011). Silicon alleviates drought stress of rice plants by improving plant water status, photosynthesis and mineral nutrient absorption. Biol. Trace Elem. Res. 142, 67-76. doi: 10.1007/s12011-0108742-x

Cornelis, J. T., Delvaux, B., and Titeux, H. (2010). Contrasting silicon uptakes by coniferous trees: a hydroponic experiment on young seedlings. Plant Soil 336, 99-106. doi: 10.1007/s11104-010-0451-x

Coskun, D., Britto, D. T., Huynh, W. Q., and Kronzucker, H. J. (2016). The role of silicon in higher plants under salinity and drought stress. Front. Plant Sci. 7:1072. doi: 10.3389/fpls.2016.01072

Gao, X., Zou, C., Wang, L., and Zhang, F. (2004). Silicon emproves water use efficiency in maize plants. J. Plant Nutr. 27, 1457-1470. doi: 10.1081/pln200025865

Gao, X., Zou, C., Wang, L., and Zhang, F. (2006). Silicon decreases transpiration rate and conductance from stomata of maize plants. J. Plant Nutr. 29, 1637-1647. doi: 10.1080/01904160600851494

Gong, H. J., and Chen, K. M. (2012). The regulatory role of silicon on water relations, photosynthetic gas exchange, and carboxylation activities of wheat leaves in field drought conditions. Acta Physiol. Plant. 34, 1589-1594. doi: 10.1007/s11738-012-0954-6

Gong, H. J., Chen, K. M., Chen, G. C., Wang, S. M., and Zhang, C. L. (2003). Effects of silicon on growth of wheat under drought. J. Plant Nutr. 26, 1055-1063. doi: 10.1081/pln-120020075

Gunes, A., Pilbeam, D. J., Inal, A., Bagci, E. G., and Coban, S. (2007). Influence of silicon on antioxidant mechanisms and lipid peroxidation in chickpea (Cicer arietinum L.) cultivars under drought stress. J. Plant Interact. 2, 105-113. doi: 10.1080/17429140701529399

Gunes, A., Pilbeam, D. J., Inal, A., and Coban, S. (2008). Influence of silicon on sunflower cultivars under drought stress, I: growth, antioxidant mechanisms, and lipid peroxidation. Commun. Soil Sci. Plant Anal. 39, 1885-1903. doi: $10.1080 / 00103620802134651$

Guntzer, F., Keller, C., and Meunier, J. D. (2012). Benefits of plant silicon for crops: a review. Agron. Sustain. Dev. 32, 201-213. doi: 10.1007/s13593-011-0039-8
Guo, B., Liu, C., Ding, N., Fu, Q., Lin, Y., Li, H., et al. (2016). Silicon alleviates cadmium toxicity in two cypress varieties by strengthening the exodermis tissues and stimulating phenolic exudation of roots. J. Plant Growth Regul. 35, 420-429. doi: 10.1007/s00344-015-9549-y

Habibi, G. (2014). Silicon supplementation improves drought tolerance in canola plants. Russ. J. Plant Physiol. 61, 784-791. doi: 10.1134/s1021443714060077

Hattori, T., Inanaga, S., Araki, H., An, P., Morita, S., Luxova, M., et al. (2005). Application of silicon enhanced drought tolerance in Sorghum bicolor. Physiol. Plant. 123, 459-466. doi: 10.1111/j.1399-3054.2005.00481.x

Hattori, T., Ishii, K., An, P., and Inanaga, S. (2009). Growth enhancement of rye by silicon application under two different soil water regimes. J. Plant Nutr. 32, 187-196. doi: 10.1080/01904160802590577

Hattori, T., Sonobe, K., Inanaga, S., An, P., Tsuji, W., Araki, H., et al. (2007). Short term stomatal responses to light intensity changes and osmotic stress in sorghum seedlings raised with and without silicon. Environ. Exp. Bot. 60, 177-182. doi: 10.1016/j.envexpbot.2006.10.004

Helaly, M. N., El-Hoseiny, H., El-Sheery, N. I., Rastogi, A., and Kalaji, H. M. (2017). Regulation and physiological role of silicon in alleviating drought stress of mango. Plant Physiol. Biochem. 118, 31-44. doi: 10.1016/j.plaphy.2017.05.021

Hernandez-Apaolaza, L. (2014). Can silicon partially alleviate micronutrient deficiency in plants? A review. Planta 240, 447-458. doi: 10.1007/s00425-0142119-x

Javot, H., and Maurel, C. (2002). The role of aquaporins in root water uptake. Ann. Bot. 90, 301-313. doi: 10.1093/aob/mcf199

Kanai, S., Moghaieb, R. E., El-Shemy, H. A., Panigrahi, R., Mohapatra, P. K., Ito, J., et al. (2011). Potassium deficiency affects water status and photosynthetic rate of the vegetative sink in green house tomato prior to its effects on source activity. Plant Sci. 180, 368-374. doi: 10.1016/j.plantsci.2010. 10.011

Kang, J., Zhao, W., and Zhu, X. (2016). Silicon improves photosynthesis and strengthens enzyme activities in the C-3 succulent xerophyte Zygophyllum xanthoxylum under drought stress. J. Plant Physiol. 199, 76-86. doi: 10.1016/ j.jplph.2016.05.009

Li, H., Zhu, Y., Hu, Y., Han, W., and Gong, H. (2015). Beneficial effects of silicon in alleviating salinity stress of tomato seedlings grown under sand culture. Acta Physiol. Plant. 37:71. doi: 10.1007/s11738-015-1818-7

Liang, Y. C., Sun, W. C., Zhu, Y. G., and Christie, P. (2007). Mechanisms of siliconmediated alleviation of abiotic stresses in higher plants: a review. Environ. Pollut. 147, 422-428. doi: 10.1016/j.envpol.2006.06.008

Liang, Y. Z. J., Li, Z., Chu, G., Ding, Y., Zhang, J., and Sun, W. (2008). Role of silicon in enhancing resistance to freezing stress in two contrasting winter wheat cultivars. Environ. Exp. Bot. 64, 286-294. doi: 10.1016/j.envexpbot.2008.06.005

Liu, H. X., and Guo, Z. G. (2013). Forage yield and water use efficiency of alfalfa applied with silicon under water deficit conditions. Philipp. Agric. Sci. 96, 370-376.

Liu, P., Yin, L., Wang, S., Zhang, M., Deng, X., Zhang, S., et al. (2015). Enhanced root hydraulic conductance by aquaporin regulation accounts for silicon alleviated salt-induced osmotic stress in Sorghum bicolor L. Environ. Exp. Bot. 111, 42-51. doi: 10.1016/j.envexpbot.2014.10.006

Liu, P., Yin, L. N., Deng, X. P., Wang, S. W., Tanaka, K., and Zhang, S. Q. (2014). Aquaporin-mediated increase in root hydraulic conductance is involved in silicon-induced improved root water uptake under osmotic stress in Sorghum bicolor L. J. Exp. Bot. 65, 4747-4756. doi: 10.1093/jxb/eru220

Luu, D. T., and Maurel, C. (2005). Aquaporins in a challenging environment: molecular gears for adjusting plant water status. Plant Cell Environ. 28, 85-96 doi: 10.1111/j.1365-3040.2004.01295.x

Ma, C. C., Li, Q. F., Gao, Y. B., and Xin, T. R. (2004). Effects of silicon application on drought resistance of cucumber plants. Soil Sci. Plant Nutr. 50, 623-632. doi: 10.1080/00380768.2004.10408520

Ma, J. F. (2004). Role of silicon in enhancing the resistance of plants to biotic and abiotic stresses. Soil Sci. Plant Nutr. 50, 11-18. doi: 10.1080/00380768.2004. 10408447

Ma, J. F., and Yamaji, N. (2006). Silicon uptake and accumulation in higher plants. Trends Plant Sci. 11, 392-397. doi: 10.1016/j.tplants.2006.06.007

Ma, J. F., and Yamaji, N. (2015). A cooperative system of silicon transport in plants. Trends Plant Sci. 20, 435-442. doi: 10.1016/j.tplants.2015.04.007

Mahajan, S., and Tuteja, N. (2005). Cold, salinity and drought stresses: an overview. Arch. Biochem. Biophys. 444, 139-158. doi: 10.1016/j.abb.2005.10.018 
Mahmood, S., Daur, I., Al-Solaimani, S. G., Ahmad, S., Madkour, M. H., Yasir, M., et al. (2016). Plant growth promoting rhizobacteria and silicon synergistically enhance salinity tolerance of mung bean. Front. Plant Sci. 7:876. doi: 10.3389/ fpls.2016.00876

Maurel, C., and Chrispeels, M. J. (2001). Aquaporins. A molecular entry into plant water relations. Plant Physiol. 125, 135-138. doi: 10.1104/pp.125. 1.135

Maurel, C., Verdoucq, L., Luu, D. T., and Santoni, V. (2008). Plant aquaporins: membrane channels with multiple integrated functions. Annu. Rev. Plant Biol. 59, 595-624. doi: 10.1146/annurev.arplant.59.032607. 092734

Meharg, C., and Meharg, A. A. (2015). Silicon, the silver bullet for mitigating biotic and abiotic stress, and improving grain quality, in rice? Environ. Exp. Bot. 120, 8-17. doi: 10.1016/j.envexpbot.2015.07.001

Ming, D. F., Pei, Z. F., Naeem, M. S., Gong, H. J., and Zhou, W. J. (2012). Silicon alleviates peg-induced water-deficit stress in upland rice seedlings by enhancing osmotic adjustment. J. Agron. Crop Sci. 198, 14-26. doi: 10.1111/j.1439-037X. 2011.00486.x

Munns, R., and Tester, M. (2008). Mechanisms of salinity tolerance. Annu. Rev. Plant Biol. 59, 651-681. doi: 10.1146/annurev.arplant.59.032607. 092911

Parveen, N., and Ashraf, M. (2010). Role of silicon in mitigating the adverse effects of salt stress on growth and photosynthetic attributes of two maize (Zea mays L.) cultivars grown hydroponically. Pak. J. Bot. 42, 1675-1684.

Pereira, T. S., da Silva Lobato, A. K., Tan, D. K. Y., da Costa, D. V., Uchôa, E. B., Ferreira, R. D. N., et al. (2013). Positive interference of silicon on water relations, nitrogen metabolism, and osmotic adjustment in two pepper (Capsicum annuum) cultivars under water deficit. Aust. J. Crop Sci. 58, 481-486.

Qin, L., Kang, W., Qi, Y., Zhang, Z., and Wang, N. (2016). The influence of silicon application on growth and photosynthesis response of salt stressed grapevines (Vitis vinifera L.). Acta Physiol. Plant. 38:68. doi: 10.1007/s11738-0162087-9

Reynolds, O. L., Padula, M. P., Zeng, R., and Gurr, G. M. (2016). Silicon: potential to promote direct and indirect effects on plant defense against arthropod pests in agriculture. Front. Plant Sci. 7:744. doi: 10.3389/fpls.2016. 00744

Rizwan, M., Ali, S., Ibrahim, M., Farid, M., Adrees, M., Bharwana, S. A., et al. (2015). Mechanisms of silicon-mediated alleviation of drought and salt stress in plants: a review. Environ. Sci. Pollut. Res. 22, 15416-15431. doi: 10.1007/s11356015-5305- $\mathrm{x}$

Romero-Aranda, M. R., Jurado, O., and Cuartero, J. (2006). Silicon alleviates the deleterious salt effect on tomato plant growth by improving plant water status. J. Plant Physiol. 163, 847-855. doi: 10.1016/j.jplph.2005. 05.010

Sacała, E. (2009). Role of silicon in plant resistance to water stress. J. Elemntol. 14, 619-630. doi: 10.5601/jelem.2009.14.3.20

Sahebi, M., Hanafi, M. M., Akmar, A. S. N., Rafii, M. Y., Azizi, P., Tengoua, F. F., et al. (2015). Importance of silicon and mechanisms of biosilica formation in plants. Biomed. Res. Int. 2015:396010. doi: 10.1155/2015/39 6010

Saud, S., Li, X., Chen, Y., Zhang, L., Fahad, S., Hussain, S., et al. (2014). Silicon application increases drought tolerance of Kentucky Bluegrass by improving plant water relations and morphophysiological functions. Sci. World J. 2014:368694. doi: 10.1155/2014/ 368694

Savant, N. K., Snyder, G. H., and Datnoff, L. E. (1996). Silicon management and sustainable rice production. Adv. Agron. 58, 151-199. doi: 10.1016/S00652113(08)60255-2

Savvas, D., Giotis, D., Chatzieustratiou, E., Bakea, M., and Patakioutas, G. (2009). Silicon supply in soilless cultivations of zucchini alleviates stress induced by salinity and powdery mildew infections. Environ. Exp. Bot. 65, 11-17. doi: 10.1016/j.envexpbot.2008.07.004

Savvas, D., Gizas, G., Karras, G., Lydakis-Simantiris, N., Salahas, G., Papadimitriou, M., et al. (2007). Interactions between silicon and $\mathrm{NaCl}$-salinity in a soilless culture of roses in greenhouse. Eur. J. Hortic. Sci. 72, 73-79.
Savvas, D., and Ntatsi, G. (2015). Biostimulant activity of silicon in horticulture. Sci. Hortic. 196, 66-81. doi: 10.1016/j.scienta.2015. 09.010

Shen, X. F., Zhou, Y. Y., Duan, L. S., Li, Z. H., Eneji, A. E., and Li, J. M. (2010). Silicon effects on photosynthesis and antioxidant parameters of soybean seedlings under drought and ultraviolet-B radiation. J. Plant Physiol. 167, 1248-1252. doi: 10.1016/j.jplph.2010.04.011

Shi, Y., Zhang, Y., Han, W., Feng, R., Hu, Y., Guo, J., et al. (2016). Silicon enhances water stress tolerance by improving root hydraulic conductance in Solanum lycopersicum L. Front. Plant Sci. 7:196. doi: 10.3389/fpls.2016. 00196

Sonobe, K., Hattori, T., An, P., Tsuji, W., Eneji, E., Kobayashi, S., et al. (2010). Effect of silicon application on sorghum root responses to weater stress. J. Plant Nutr. 34, 71-82. doi: 10.1080/01904167.2011.531360

Sonobe, K., Hattori, T., An, P., Tsuji, W., Eneji, E., Tanaka, K., et al. (2009). Diurnal variations in photosynthesis, stomatal conductance and leaf water relation in Sorghum grown with or without silicon under water stress. J. Plant Nutr. 32, 433-442. doi: 10.1080/019041608026 60743

Steudle, E. (2000). Water uptake by roots: effects of water deficit. J. Exp. Bot. 51, 1531-1542. doi: 10.1093/jexbot/51.350.1531

Sutka, M., Li, G., Boudet, J., Boursiac, Y., Doumas, P., and Maurel, C. (2011). Natural variation of root hydraulics in Arabidopsis grown in normal and salt-stressed conditions. Plant Physiol. 155, 1264-1276. doi: 10.1104/pp.110. 163113

Tuna, A. L., Kaya, C., Higgs, D., Murillo-Amador, B., Aydemir, S., and Girgin, A. R. (2008). Silicon improves salinity tolerance in wheat plants. Environ. Exp. Bot. 62, 10-16. doi: 10.1016/j.envexpbot.2007. 06.006

Ueno, O., and Agarie, S. (2005). Silica deposition in cell walls of the stomatal apparatus of rice leaves. Plant Prod. Sci. 8, 71-73. doi: 10.1626/pps.8.71

Vandeleur, R. K., Mayo, G., Shelden, M. C., Gilliham, M., Kaiser, B. N., and Tyerman, S. D. (2009). The role of plasma membrane intrinsic protein aquaporins in water transport through roots: diurnal and drought stress responses reveal different strategies between isohydric and anisohydric cultivars of grapevine. Plant Physiol. 149, 445-460. doi: 10.1104/pp.108. 128645

Verslues, P. E., Agarwal, M., Katiyar-Agarwal, S., Zhu, J., and Zhu, J. K. (2006). Methods and concepts in quantifying resistance to drought, salt and freezing, abiotic stresses that affect plant water status. Plant J. 45, 523-539. doi: 10.1111/ j.1365-313X.2005.02593.x

Vivancos, J., Labbe, C., Menzies, J. G., and Belanger, R. R. (2015). Silicon-mediated resistance of Arabidopsis against powdery mildew involves mechanisms other than the salicylic acid (SA)-dependent defence pathway. Mol. Plant Pathol. 16, 572-582. doi: 10.1111/mpp.12213

Wang, S., Liu, P., Chen, D., Yin, L., Li, H., and Deng, X. (2015). Silicon enhanced salt tolerance by improving the root water uptake and decreasing the ion toxicity in cucumber. Front. Plant Sci. 6:759. doi: 10.3389/fpls.2015.00759

Wang, Y., and Wu, W.-H. (2013). Potassium transport and signaling in higher plants. Annu. Rev. Plant Biol. 64, 451-476. doi: 10.1146/annurev-arplant050312-120153

Yeo, A. R., Flowers, S. A., Rao, G., Welfare, K., Senanayake, N., and Flowers, T. J. (1999). Silicon reduces sodium uptake in rice (Oryza sativa L.) in saline conditions and this is accounted for by a reduction in the transpirational bypass flow. Plant Cell Environ. 22, 559-565. doi: 10.1046/j.1365-3040.1999.00418.x

Yin, L. N., Wang, S. W., Li, J. Y., Tanaka, K., and Oka, M. (2013). Application of silicon improves salt tolerance through ameliorating osmotic and ionic stresses in the seedling of Sorghum bicolor. Acta Physiol. Plant. 35, 3099-3107. doi: $10.1007 / \mathrm{s} 11738-013-1343-5$

Yoshida, S. (1965). Chemical aspects of the role of silicon in physiology of the rice plant. Bull. Natl. Inst. Agric. Sci. B 15, 1-58.

Zhang, C., Moutinho-Pereira, J. M., Correia, C., and Coutinho, J. (2013). Foliar application of Sili- $\mathrm{K}^{\circledR}$ increases chestnut (Castanea spp.) growth and photosynthesis, simultaneously increasing susceptibility to water deficit. Plant Soil 365, 211-225. doi: 10.1007/s11104-0121385-2d

Zhang, Q., Yan, C., Liu, J., Lu, H., Duan, H., Du, J., et al. (2014). Silicon alleviation of cadmium toxicity in mangrove (Avicennia marina) in relation to cadmium 
compartmentation. J. Plant Growth Regul. 33, 233-242. doi: 10.1007/s00344013-9366-0

Zhu, Y., and Gong, H. (2014). Beneficial effects of silicon on salt and drought tolerance in plants. Agron. Sustain. Dev. 34, 455-472. doi: 10.1007/s13593-0130194-1

Zhu, Y., Xu, X., Hu, Y., Han, W., Yin, J., Li, H., et al. (2015). Silicon improves salt tolerance by increasing root water uptake in Cucumis sativus L. Plant Cell Rep. 34, 1629-1646. doi: 10.1007/s00299-015-1814-9

Zuccarini, P. (2008). Effects of silicon on photosynthesis, water relations and nutrient uptake of Phaseolus vulgaris under $\mathrm{NaCl}$ stress. Biol. Plant. 52, 157-160. doi: 10.1007/s10535-008-0034-3
Conflict of Interest Statement: The authors declare that the research was conducted in the absence of any commercial or financial relationships that could be construed as a potential conflict of interest.

Copyright (C) 2018 Chen, Wang, Yin and Deng. This is an open-access article distributed under the terms of the Creative Commons Attribution License (CC BY). The use, distribution or reproduction in other forums is permitted, provided the original author(s) and the copyright owner are credited and that the original publication in this journal is cited, in accordance with accepted academic practice. No use, distribution or reproduction is permitted which does not comply with these terms. 